\title{
A Study of Personality Subtypes in Obese Patients Seeking Treatment
}

\author{
Salvatore Gullo ${ }^{1 凶}$, Gianluca Lo Coco $^{1}$, Laura Salerno ${ }^{1}$, Federica La Pietra ${ }^{1}$, \& Vincenzo Bruno ${ }^{2}$
}

\begin{abstract}
Previous research has not been able to identify a distinct personality style that refers specifically to obese individuals. The purpose of this investigation was to explore whether different personality-based groups can be identified in obese individuals, as has been shown with eating disorder patients. Data were collected from 149 obese patients $(\mathrm{BMI}=37.3, \pm 6.4 ; 83 \%$ female $)$ seeking dietary treatment and psychological support for their weight problems. Participants completed the Millon Clinical Multiaxial Inventory III (MCMI-III; Millon, 1997) and a battery of eight measures assessing psychological distress, mood states, eating behaviors, obesity-related quality of life, and interpersonal problems. The MCMI-III personality scales were cluster analysed to classify participants into personality subtypes. Three personality clusters were retained (externalizing, internalizing, high-functioning), and several differences in the validating variables emerged across the three personality subtypes. The internalizing group reported the greatest level of personality distress and an increased likelihood of poor psychosocial functioning and high eating behavior symptoms. Findings support the clinical utility of personality subtypes in obesity. Future work is needed to identify causal pathways between personality typologies and eating disorders in obese individuals.
\end{abstract}

Keywords: obesity, personality typologies, MCMI-III, personality disorders, cluster analysis

Obesity is becoming a significant problem for many countries around the world (World Health Organization, 2000). Rates of obesity have reached epidemic levels, and conservative estimates indicate that $35 \%$ of the US population are obese (Flegal, Carroll, Ogden, \& Curtin, 2010). Similarly, obesity rates have risen in every European country, in Australia and in Canada (OECD, 2009). Obesity is usually measured by the body mass index (or BMI; which is defined as $\mathrm{kg} / \mathrm{m}^{2}$ ). Adults with a BMI above 30 are labelled as obese. Although current data do not support the idea that obesity is a mental disorder, epidemiologic reviews have documented an association between disordered eating and obesity (Marcus \& Wildes, 2009).

A good deal of research has focused on the associations between personality traits and disorders (PDs)

\footnotetext{
${ }^{1}$ Department of Psychology, University of Palermo, Italy. ${ }^{2}$ Mental Health Department, Eating Disorders Centre (Ce.Di.Al), ASP 6 Palermo.

$\triangle$ Correspondence concerning this paper should be addressed to Salvatore Gullo, Viale delle Scienza, Edificio 15, $90100 \mathrm{~Pa}$ lermo, Italy. E-mail: salvo.9g@gmail.com
}

and eating behaviors and disorders (Cassin \& von Ranson, 2005), but extensions of these studies to obese individuals have been limited. It was suggested that personality traits may give a fuller understanding of eating behaviors in obesity (Elfhag \& Morey, 2008). Previous research has not been able to identify a distinct personality style, measured by self-report questionnaires, that characterizes obese individuals (Friedman \& Brownell, 1995), but it was suggested that particular personality dimensions could be related to specific behavioral correlates of obesity. Studies that have measured personality traits using self-report questionnaires show a difference between lean and obese persons, and between obese persons who enroll and who do not enroll in weight management programs (Rydén et al., 2004; Sullivan, Cloninger, Przybeck, \& Klein, 2007). Studies with Big-Five personality factors indicated that particular dimensions of personality are reflected in the eating behaviors of obese subjects: Provencher and colleagues (2008) indicated that a higher level of neuroticism was a significant predictor of higher scores for cognitive dietary restraint, and susceptibility to hunger, whereas Magee and Heaven (2011) using the Big Five Test found that 
Extraversion and Neuroticism were cross-sectionally associated with obesity.

With regard to personality disorders, the results of a large nationally representative US sample highlighted that being obese was associated with increased rates of cluster A and cluster B personality disorders, and that extreme obesity was positively associated with antisocial and avoidant personality disorders in particular (Mather, Cox, Enns, \& Sareen, 2008), whereas Kalarchian et al. (2007) found that the most common class of personality disorder in a sample of obese individuals seeking surgery was cluster $\mathrm{C}$ personality disorders, characterized by anxious (avoidant) or fearful (obsessive-compulsive). Some authors have suggested that binge behavior could play an important role in personality differences among obese individuals. Some studies have found that obese patients with Binge Eating Disorders (BED) have elevated rates of avoidant personality disorder as measured by the SCID-II for DSM-III-R (Wilfley et al., 2000). It is noteworthy that obesity has shown a positive association with depression (Luppino et al., 2010), with several lifetime mood and anxiety disorders (Kasen, Cohen, Chen, \& Must, 2008; Pickering, Grant, Chou, \& Compton, 2007), and with interpersonal problems (Lo Coco, Gullo, Salerno, \& Iacoponelli, 2011a) though the mechanism of these associations remains uncertain. Moreover, some particular personality traits and coping strategies (such as neuroticism, agreeableness and emotion mastery) seem to characterize specific subgroups of obese individuals (Gagnon-Girouard et al., 2010).

Finally, most research that has taken a typological approach to understanding personality heterogeneity among individuals with eating-related psychopathology has shown that empirically based classification of eating disorders (EDs) (Wonderlich, Joiner, Keel, Williamson, \& Crosby, 2007), as well as the personality classification of EDs based on empirically derived groups of traits, may have utility in terms of clinical course and response to treatment. A growing body of empirical studies supports the idea that EDs may be comprised of different personality-based classes (Thompson-Brenner \& Westen, 2005): a highfunctioning subtype characterized by minimal personality pathology, an emotionally dysregulated subtype with borderline and histrionic traits (i.e., emotional instability), or an avoidant-internalizing subtype with anxious, depressed, and socially avoidant tendencies. It remains to be demonstrated that similar personality-based groups can be identified in obese individuals, as has been shown with ED patients. In this study, we used cluster analysis to examine whether the three specific types of personality style found in the literature would emerge using the Millon Clinical Multiaxial Inventory III (MCMI-III; Millon, 1997) in a sample of treatment-seeking obese individuals. To our knowledge, no clustering analyses based on these three personality dimensions have been performed among overweight and obese groups of individuals. In addition, the current study aimed to extend previous re- search characterizing personality heterogeneity in individuals with eating disturbance to obese individuals from the perspective of Millon's model of personality.

Accordingly, we addressed two research questions: (1) does the three personality-based cluster solution (high-functioning, emotionally dysregulated, and avoidant-internalizing) apply to a sample of treatment-seeking obese patients? And (2) are the three personality-based groups of obese individuals different on psychological features, eating attitudes and behaviors?

\section{Method}

\section{Participants and procedure}

Study participants included 149 obese patients (124 female and 25 males), with a mean age $=44.57(\mathrm{SD}=$ 14.34), seeking dietary treatment and psychological support for their weight problems. The BMI ranged from 30.1 to $60.4 \mathrm{Kg} / \mathrm{m}^{2}(M=37.3$; $\mathrm{SD}=6.4)$. Participants were recruited at baseline in an Italian mental health care service specializing in eating disorders (the hospital "Ce.Di.Al" of the ASP in Palermo, Italy). Twenty-eight percent of participants were single, $61 \%$ were married; $97 \%$ of participants had high school education (10-12 years of school). No participants displayed metabolic disorders or met the DSM-IV diagnostic criteria for eating disorders; moreover, they were not under pharmacological treatment for weightrelated diseases. Prior to their participation in the study, each participant signed an informed consent document approved by the Palermo University Research Ethics Committee.

\section{Measures}

The psychological assessment of the participants was carried out by means of the self-report scales described below.

The Millon Clinical Multiaxial Inventory III (MCMI-III; Millon, 1997) is a self-report measure of DSM-IV related personality disorders and clinical syndromes. It consists of 175 true/false items with 28 scales measuring basic personality style and clinical syndromes. For the aim of this study we used only the 14 Personality Disorder Scales: Schizoid, Avoidant, Depressive, Dependent, Histrionic, Narcissistic, Antisocial, Aggressive-sadistic, Compulsive, Passiveaggressive, Self-defeating, Schizotypal, Borderline, and Paranoid. The MCMI-III raw scores are transformed and reported as weighted Base Rate (BR) scores. The Base Rate scores vary from 1 to 115 , with a median score of 60 . Scores between 75 and 84 indicate significant personality trait or mental health concern, and scores of 85 or above indicate a persistent, significant clinical concern or personality disorder. Good internal consistency (Cronbach's alpha range for subscales $=.66$ -.90 ) and stability (test-retest $r=.84-.96$ ) have been found for the Italian version of the MCMI-III scales 
(Zennaro, Ferracuti, Lang, \& Sanavio, 2008).

The Eating Disorder Inventory-2 (EDI-2; Garner, 1995 ) is a 91-item self-report measure that evaluates symptoms, psychological characteristics and disordered eating attitudes common to individuals with eating behavior disorders. Higher scores on EDI-2 scales indicated higher levels of eating disturbance. In the current study, the Italian version of the EDI-2 was used (Garner, 1995), and Cronbach's alpha for subscales ranged from .79 to .86 .

The Obesity Related Well-Being (OR-WELL; Mannucci et. al, 1999) is a self-report measure assessing the obese patients quality of life. This test is made up of eighteen questions conceptually related to three different areas: symptoms (obesity-related somatic symptoms), discomfort (impact of obesity on the patients' emotional status) and impact (effects of obesity on familial relationship and role functioning). Higher OR-WELL 97 scores indicate a lower quality of life. The internal consistency coefficient of the OR-WELL 97 in the current study ranged from .82 to .84 .

The Binge Eating Scale (BES; Gormally, Black, Daston, \& Rardin, 1982) is a 16-item self-report questionnaire that assesses symptoms of binge eating. Higher scores indicate greater degree of binge eating severity. The scale has adequate internal consistency and validity. The Cronbach's alpha for the BES in the current study was 91 .

The Rosenberg Self-Esteem Scale (RSES; Rosenberg, 1965 ) is used to assess clients' levels of self-esteem. The RSES is a widely used 10- item questionnaire that measures global self-esteem. A higher score indicates more positive self-esteem. Scores below 21 indicate low self-esteem. In the current study, the Italian version of the RSES was used (Prezza, Trombaccia, \& Armento, 1997), and its Cronbach's alpha was .87.

The Inventory of Interpersonal Problems-short version (IIP-32; Horowitz, Alden, Wiggins, \& Pincus, 2000 ) is a 32-item self-report inventory developed to assess patient social adjustment and interpersonal difficulties. High values on IIP-32 T-scores are indicative of poorer interpersonal functioning. In the current study the Cronbach's alpha estimates for the eight IIP-32 subscales scores ranged from .80 to .89 .

The Outcome Questionnaire (OQ-45; Lambert et al., 2004 ) is a 45-item, self-report measure of psychological functioning. The range of scores possible on the OQ-45 is $0-180$, with higher scores reflecting more severe distress. The Italian version of the instrument showed good psychometric properties (Chiappelli, Lo Coco, Gullo, Bensi, \& Prestano, 2008). In the current study, its Cronbach's alpha was 89 for the total score.

The Profile of Mood States (POMS; McNair, Lorr, \& Droppelman, 1971) is a 65-item measure of dysfunctional affect or mood. We used POMS score on three domains: anxiety, depression, and hostility. In the current study, its Cronbach's alpha ranged from .79 to .85 .

The Body Influence Assessment Inventory (BIAI; Osman et al., 2006) is a 28-item self report inventory, that taps dimensions of bodily experiences in the eating dis- orders area, such as negative affects about appearance, and physical appearance practices. The BIAI has shown good psychometric properties, and its Cronbach's alpha estimates ranged from .81 to .90 . In the current study, Cronbach's alpha ranged from .77 to .86 .

\section{Analytical Strategies}

Standardized MCMI-III personality pattern scale data for 149 obese patients were submitted to Ward's method of hierarchical cluster analysis and K-Means cluster analysis technique to identify potential groups. The aim in Ward's method is to join cases into clusters such that the variance within a cluster is minimized. K-Means cluster analysis is a method of classifying people into typologies by determining clusters of participants that display small within-cluster variation relative to the between-cluster variation (Dillon \& Goldstein, 1984). The K-Means method will produce the exact $k$ different clusters demanded for greatest possible distinction.

Hierarchical cluster analysis (Ward's method) starts with each case as a separate cluster, that is, there are as many clusters as cases, and then combines the clusters sequentially, reducing the number of clusters at each step until only one cluster is left. The clusters are linked at increasing levels of dissimilarity. Hierarchical cluster analysis provides an agglomeration coefficient; the changes in this coefficient determine the optimum number of clusters step.

Results showed that for one cluster we had an agglomeration coefficient of 1907.86 , for two clusters of 1616.82, for three clusters of 1221.96, and for four clusters of 1045.39. In this approach, small variations in the agglomeration coefficient indicate that fairly homogeneous clusters are being merged. Changes in the agglomeration coefficient at each step show that the maximum distance is between 3- and 2-clusters: it appears that the 3-cluster solution was better than other solutions, because successive clustering adds far less to distinguishing between cases. Afterward, the results of the K-means cluster analysis reassigned each participant to one of three clusters.

Finally, in order to establish internal validity of the clusters, a MANOVA was conducted with the clusters as independent variables. Where significant F-values occured, Tukey post hoc comparisons were conducted to determine the simple effects between clusters. Cluster labels were assigned for each cluster based upon their personality profile on the MCMI-III.

\section{Results}

Three clusters of the MCMI III were retained to identify personality-based groups of obese individuals (Table 1). The three clusters did not differ by age or sex distribution. The first and largest group $(n=60$; $40.3 \%$ ) was characterized by moderately high scores on Passive-aggressive, Aggressive-sadistic, and Antisocial scales. This pattern suggests a group of obese in- 
Table 1. Base Rate (BR) mean scores for each personality scale of the MCMI-III across clusters

\begin{tabular}{|c|c|c|c|c|}
\hline \multirow[b]{2}{*}{ MCMI-III Personality scales } & \multirow[b]{2}{*}{$\begin{array}{l}\text { Overall Sample } \\
\quad(N=149)\end{array}$} & \multicolumn{2}{|c|}{ Cluster } & \multirow[b]{2}{*}{$\begin{array}{l}\text { High Functioning } \\
\qquad(n=39)\end{array}$} \\
\hline & & $\begin{array}{l}\text { Externalizing } \\
\quad(n=60)\end{array}$ & $\begin{array}{l}\text { Internalizing } \\
\quad(n=50)\end{array}$ & \\
\hline Schizoid & 61 & 59 & 76 & 42 \\
\hline Avoidant & 51 & 47 & 76 & 22 \\
\hline Depressive & 53 & 44 & 89 & 18 \\
\hline Dependent & 52 & 47 & 79 & 22 \\
\hline Histrionic & 58 & 54 & 45 & 66 \\
\hline Narcissistic & 54 & 51 & 47 & 56 \\
\hline Antisocial & 51 & 62 & 64 & 27 \\
\hline Sadistic (Aggressive) & 56 & 62 & 66 & 38 \\
\hline Compulsive & 56 & 57 & 54 & 62 \\
\hline Negativistic (Passive-Aggressive) & 62 & 64 & 81 & 36 \\
\hline Masochistic (Self-Defeating) & 49 & 43 & 81 & 12 \\
\hline Schizotypal & 47 & 47 & 67 & 17 \\
\hline Borderline & 47 & 45 & 71 & 18 \\
\hline Paranoid & 53 & 58 & 69 & 24 \\
\hline
\end{tabular}

dividuals who are aggressive, sadistic, impulsive, and with a tendency to act out emotionally, supporting the label "externalizing". The second group ( $n=50$; $33.6 \%)$ reported the greatest level of personality distress, with high scores for Schizoid, Avoidant, Depressive, Dependent scales. In addition, this group showed high sores on Passive-Aggressive, and Masochistic scales. Overall, these scores suggest a group of obese individuals who are socially avoidant, inhibited, dependent, depressive, and with aggressive tendencies directed toward the self, supporting the label "internalizing". Moreover, this cluster had moderate to high mean scores on antisocial and sadistic personality scales too. The third and smallest group ( $n=39$; 26.1\%) was characterized by Histrionic, Compulsive, and Narcissistic, scales. This cluster's mean profile included no clinical elevations, suggesting "high functioning" individuals who are self-centered, and turn to themselves or others to cope with stress.

Table 2 presents validation analyses of the three clustered subtypes on psychological distress, obesity-related quality of life, eating and binge behaviors. The results of a MANOVA for the differences between clusters show that the "internalizing" group reported the greatest level of psychological distress, with high scores on depression (POMS D), anxiety (POMS A), poor psychological functioning (OQ-45), and interpersonal problems (IIP32). Moreover, obese individuals in cluster 2 (internalizing group) reported higher scores on eating concerns (BIAI, BES, EDI-2, OR-WELL) than individuals in cluster 1 (externalizing group). Obese subjects of the high functioning group, as expected, did not report elevated scores on the validating variables. Finally, the three clustered subtypes did not differ in current BMI.

\section{Discussion}

The primary aim of the study was to investigate an empirically-based categorisation based on Millon's model of personality among treatment-seeking overweight/obese individuals. Current results indicated that obese subjects were not homogeneous with regard to personality typologies, consistent with previous studies which have not been able to identify a distinct personality style that refers specifically to obese individuals (Lo Coco, Gullo, Scrima, \& Bruno, 2011b; Rydén et al., 2004). In this study, cluster analysis yielded three MCMI-III personality profiles. The first and largest group labeled externalizing comprised $41.6 \%$ of our sample. High scores on Passive-aggressive, Aggressive-sadistic, and Antisocial scales characterize these obese individuals. Although scores on these three scales were not high enough to indicate that these personality syndromes are fully present for members of this cluster, it could be suggested that individuals with this profile do not like being controlled and are prone to impulsivity.

The second and most disturbed group labeled internalizing comprised $32 \%$ of our sample. Characteristics of this profile included clinical elevation on Schizoid, Avoidant, Depressive, and Dependent scales. The members of this cluster appear to be characterized by social isolation, withdrawal, and anxiety. The third and smalles $t$ group supported the label high functioning, and comprised $26.3 \%$ of our sample. The members of this cluster may be described as self-centered obese individuals: these participants' scores on Histrionic, Compulsive, and Narcissistic scales are consistent with the high-functioning group described in earlier studi- 
Table 2. Means and standard deviations for variables across clusters

\begin{tabular}{|c|c|c|c|c|c|c|c|c|}
\hline \multirow[b]{2}{*}{ Variables } & \multicolumn{2}{|c|}{$\begin{array}{l}\text { Externalizing } \\
\quad(n=60)\end{array}$} & \multicolumn{2}{|c|}{$\begin{array}{l}\text { Internalizing } \\
\quad(n=50)\end{array}$} & \multicolumn{2}{|c|}{$\begin{array}{l}\text { High Functioning } \\
\qquad(n=39)\end{array}$} & \multicolumn{2}{|c|}{ Statistics } \\
\hline & M & $(\mathrm{SD})$ & M & $(\mathrm{SD})$ & M & $(\mathrm{SD})$ & $F$ & Partial $\eta^{2}$ \\
\hline RSES & $20.12^{\mathrm{a}}$ & $(4.35)$ & $14.87^{\mathrm{b}}$ & (5.09) & $22.53^{c}$ & $(4.54)$ & $32.48^{* *}$ & 0.31 \\
\hline BIAI & $50.87^{\mathrm{a}}$ & $(10.18)$ & $55.24^{\mathrm{a}}$ & $(10.65)$ & $46.21^{\mathrm{b}}$ & $(9.99)$ & $9.07^{* *}$ & 0.11 \\
\hline POMS Tension-anxiety & $57.22^{\mathrm{a}}$ & $(9.90)$ & $62.98^{\mathrm{b}}$ & $(11.50)$ & $51.66^{c}$ & $(10.22)$ & $13.59^{* *}$ & 0.16 \\
\hline POMS Depression & $58.18^{\mathrm{a}}$ & $(11.74)$ & $67.91^{\mathrm{b}}$ & $(14.68)$ & $52.61^{c}$ & $(9.32)$ & $19.81^{* *}$ & 0.22 \\
\hline POMS Anger-hostility & $59.37^{a}$ & $(13.17)$ & $67.02^{\mathrm{b}}$ & $(14.35)$ & $52.26^{c}$ & $(9.09)$ & $16.39^{* *}$ & 0.18 \\
\hline BES & $14.85^{\mathrm{a}}$ & $(9.48)$ & $20.24^{\mathrm{b}}$ & $(9.81)$ & $12.34^{\mathrm{a}}$ & $(8.69)$ & $8.07^{* *}$ & 0.10 \\
\hline IIP-32 & $53.23^{\mathrm{a}}$ & $(6.05)$ & $59.98^{\mathrm{b}}$ & $(8.77)$ & $47.13^{c}$ & $(9.55)$ & $26.95^{* *}$ & 0.27 \\
\hline OQ-45 & $60.95^{\mathrm{a}}$ & $(17.91)$ & $81.54^{\mathrm{b}}$ & $(19.40)$ & $45.16^{c}$ & $(19.16)$ & $45.58^{* *}$ & 0.39 \\
\hline EDI Drive for thinness & $8.72^{\mathrm{a}}$ & $(6.03)$ & $9.07^{\mathrm{a}}$ & $(6.45)$ & $6.58^{\mathrm{a}}$ & $(5.51)$ & 1.66 & 0.02 \\
\hline EDI Bulimia & $2.47^{\mathrm{a}}$ & $(3.16)$ & $4.67^{b}$ & $(4.82)$ & $1.76^{\mathrm{a}}$ & $(2.92)$ & $5.46^{*}$ & 0.07 \\
\hline EDI Body dissatisfaction & $15.52^{\mathrm{a}}$ & $(7.01)$ & $16.65^{\mathrm{a}}$ & $(7.19)$ & $13.03^{\mathrm{a}}$ & $(8.46)$ & 2.48 & 0.03 \\
\hline EDI Ineffectiveness & $3.85^{\mathrm{a}}$ & $(3.66)$ & $10.13^{\mathrm{b}}$ & $(8.52)$ & $2.87^{\mathrm{a}}$ & $(5.02)$ & $18.64^{* *}$ & 0.21 \\
\hline EDI Perfectionism & $2.83^{\mathrm{a}}$ & $(2.37)$ & $5.24^{\mathrm{b}}$ & $(4.76)$ & $3.00^{\mathrm{a}}$ & $(3.88)$ & $5.64^{* *}$ & 0.07 \\
\hline EDI Interoceptive awareness & $3.63^{\mathrm{a}}$ & $(3.06)$ & $6.15^{\mathrm{ab}}$ & $(4.83)$ & $4.26^{\mathrm{ac}}$ & $(4.28)$ & $4.78^{* *}$ & 0.06 \\
\hline EDI Interpersonal dist. & $4.28^{\mathrm{a}}$ & $(3.96)$ & $8.33^{\mathrm{b}}$ & $(6.94)$ & $2.37^{\mathrm{a}}$ & $(3.69)$ & $11.29^{* *}$ & 0.14 \\
\hline EDI Maturity fears & $4.93^{\mathrm{a}}$ & $(4.18)$ & $7.09^{\mathrm{b}}$ & $(5.17)$ & $4.00^{\mathrm{a}}$ & $(3.61)$ & $3.58^{*}$ & 0.05 \\
\hline EDI Asceticism & $5.27^{\mathrm{a}}$ & $(4.10)$ & $6.09^{\mathrm{ab}}$ & $(4.85)$ & $3.58^{\mathrm{ac}}$ & $(3.01)$ & $3.01^{*}$ & 0.04 \\
\hline EDI Impulse regulation & $2.40^{\mathrm{a}}$ & $(2.34)$ & $6.72^{\mathrm{b}}$ & $(6.67)$ & $1.24^{\mathrm{a}}$ & $(3.34)$ & $15.48^{* *}$ & 0.18 \\
\hline EDI Social insecurity & $4.32^{\mathrm{a}}$ & $(2.81)$ & $7.57^{b}$ & $(4.83)$ & $3.68^{a}$ & $(5.07)$ & $8.16^{* *}$ & 0.10 \\
\hline OR-WELL & $41.50^{\mathrm{a}}$ & $(25.66)$ & $60.24^{\mathrm{b}}$ & $(27.79)$ & $29.37^{c}$ & $(21.75)$ & $17.99^{* *}$ & 0.20 \\
\hline
\end{tabular}

Note. RSES: Rosenberg Self-Esteem Scale; BIAI: Body Influence Assessment Inventory; POMS: Profile of Mood States; BES: Binge Eating Scale; IIP-32: Inventory of Interpersonal Problems; OQ-45: Outcome Questionnaire; EDI-2: Eating Disorder Inventory; OR-WELL: Obesity Related Well-Being.

${ }^{*} p<.05{ }^{* *} p<.01$. Means sharing common superscripts ( $\mathrm{a}, \mathrm{b}$ or $\mathrm{c}$ ) do not differ significantly at the 0.05 level.

es with the MCMI. For example, in Espelage, Mazzeo, Sherman, and Thompson's study (2002), the highfunctioning group manifested no clinical elevation on the MCMI; and the characteristics of this profile included histrionic (mean $\mathrm{BR}=67.68$ ) and compulsive (mean BR $=58.03$ ) personality styles. Moreover, in the current study further support for the highfunctioning cluster was demonstrated when these obese individuals reported higher scores on selfesteem, quality of life, and lower scores on psychological distress than the other two clusters.

Taken together, these findings are consistent with most research that has taken a typological approach to understanding personality heterogeneity among eating-disturbed samples. As noted in the introduction, several studies with ED samples have consistently suggested the presence of a high-functioning subtype with minimal personality pathology; an emotionally dysregulated subtype with borderline tendencies and emotional instability; an avoidant-insecure subtype with anxious, depressed, and socially avoidant tendencies (Thompson-Brenner et al., 2005). This study ex- tends previous research in this area by supporting the presence of these three personality dimensions among treatment-seeking obese individuals. In the current study, the number of clusters was empirically and statistically identified and the obese participants were assigned to one of the three clusters by the $k$-mean procedure. From a clinical point of view, each group profile was characterized by personality scores, which are above the mean of the overall sample. Although there is support for these personality-based groups, overall, the nature of these personality typologies in obese patients appears to be more complex than this model would suggest. For example, the Borderline scores (mean BR $=71$ ) of subjects belonging to the internalizing group were unexpected. But in the final cluster solution, the internalizing cluster was characterized by means scores above the cut-off $(B R=75)$, and the borderline mean score was lower (and below the cutoff) than the other scales mentioned; therefore, we could speculate that the borderline tendencies were less representative of the personality functioning of the obese individuals in this internalizing group. Fur- 
ther research should use other empirical and statistical methods to replicate and extend our findings.

In addition, obese participants manifested different clinical elevations on the personality subscales. With regard to personality disorders, it is noteworthy that obese individuals in cluster 2 reported comorbidity with personality syndromes. Their MCMI-III Base Rate scores for the Schizoid, Avoidant, Depressive, Dependent, Passive Aggressive, and Self-Defeating scales indicate the presence of a clinically significant personality style, suggesting a worse pretreatment condition, and greater disability than obese subjects in clusters 1 and 3. Other studies supported similar high prevalence rates of personality disorders in obese patients seeking treatment (Carpiniello et al., 2009).

Despite the fact that there is evidence that antisocial, avoidant, schizoid, and obsessive-compulsive personality disorders are associated with obesity (Petry, Barry, Pietrzak, \& Wagner, 2008), our results of a cluster analytic investigation seem to support the view that internalizing obese individuals report high levels of personality disorders. This finding is consistent with studies, involving other eating disorders, which have found that the internalizing group had the highest scores on domains such as hopelessness, suicidality and depression (Krueger, 1999), and the most consistent baseline associations with poor functioning, prior major depression, and hospitalization (Thompson-Brenner et al., 2008). Further research may examine whether the presence and severity of personality pathology in treatment seeking obese people may affect their response to treatment. Although the presence of personality disorders has been shown to predict less success in weight loss for obese individuals after bariatric surgery (Kinzl et al., 2006), there is still a dearth of research conducted exploring the impact of personality disorders on the outcome of psychological treatment with obese clients. Additional longitudinal research might investigate whether obese individuals who present with an internalizing personality style have the poorest global outcome, similar to previous studies with ED samples (Thompson-Brenner et al., 2008). In addition, it is important here to mention that in our study, only a subset of obese individuals are clinically disturbed and that measuring a client's level of disturbance at intake would allow clinicians to direct resources towards those individuals rather than towards all those who enter treatment. For example, assessment might usefully focus on the presence of avoidant personality features, such as very low selfesteem, limited friendships, and social anxiety, and target these particular issues among the obese population.

The results of the current study seem to support that personality heterogeneity might affect the comorbidity patterning of eating disorders among obese subjects. For example, we observed that the internalizing individuals in the current sample had an increased likelihood of poor psychosocial functioning (i.e., poor self-esteem, poor quality of life, high psychological distress) and high ED symptoms (i.e., binge be- haviours, ineffectiveness, and impulsiveness), whereas the high functioning individuals had the fewest problems across several domains. Studies to determine causal pathways between specific disorders and personality typologies in obese individuals are clearly needed.

Interestingly, with respect to the BMI, we found no differences across the 3 subgroups. This finding tends to support the view that personality typologies/disorders appear to be more closely associated with general psychopathology and functioning than with the overweight level per se. Our results are consistent with studies, involving obese individuals with $\mathrm{BED}$, which have found a relationship between personality pathology and certain features of eating disorder psychopathology (Wilfley et al., 2000).

Our conclusions must be interpreted in the light of some methodological limitations. Due to the crosssectional nature of the data, causal inferences cannot be made. Second, our conclusions must be tempered by the fact that we do not know whether these three clusters are unique to obese people seeking treatment because of the lack of any control group. Third, our study relied on self-report measures that may be susceptible to various biases. Further research with the use of multimodal assessment is warranted. Fourth, the sample consisted of obese individuals presenting for treatment at a mental health-care service specialized in eating disorders. Research suggests that obese treatment-seeking persons may differ from obese individuals in the community. As such, these results may not generalize to obese individuals who are not treatment-seeking. Finally, the power of the study is limited by the large amount of statistical analyses.

In summary, this investigation provides initial evidence that three personality-based groups can be identified in obese individuals. In the light of these results, we believe that individualized care in accordance with personality type could improve our understanding of eating behaviours in obesity. In treatment-seeking obese individuals, the internalizing traits should be monitored and targeted in the treatment of weight disorders, and should be continuously examined for their role in the maintenance of these disorders. Finally, we sincerely hope this work inspires future research to identify the relations between personality typologies and obesity and to clearly foster a more effective client-centered treatment approach.

\section{Acknowledgement}

Dr Lo Coco was supported, in part, by PRIN grant no. 2008A4F8KC_004 from the Ministry of Education University and Research (MIUR).

\section{References}

Carpiniello, B., Pinna, F., Pillai, G., Nonnoi, V., Pisano, E., Corrias, S., ... Loviselli, A. (2009). Obesity and psychopathology. A study of psychiatric comorbidity among patients attending a specialist obesity unit. Epidemiologia e Psichiatria Sociale, 18, 119-127. doi:10.1017/S1121189X00001007 
Cassin, S. E., \& von Ranson, K. M. (2005). Personality and eating disorders: A decade in review. Clinical Psychology Review, 25, 895-916. doi: 10.1016/j.cpr.2005.04.012

Chiappelli, M., Lo Coco, G., Gullo, S., Bensi, L., \& Prestano, C. (2008) L'outcome questionnaire 45.2. Adattamento italiano di uno strumento per la valutazione dei trattamenti psicologici [The Outcome Questionnaire 45.2. Italian validation of an instrument for the assessment of psychological treatments]. Epidemiologia e Psichiatria Sociale, 17, 152-161. doi: 10.1017/S1121189X00002852

Dillon, W., \& Goldstein, M. (1984). Multivariate analysis methods and applications. New York: John Wiley.

Elfhag, K., \& Morey, L. C. (2008). Personality traits and eating behavior in the obese: poor self-control in emotional and external eating but personality assets in restrained eating. Eating Behaviors, 9, 285-293. doi: 10.1016/j.eatbeh.2007.10.003

Espelage, D. L., Mazzeo, S. E., Sherman, R., \& Thompson, R. (2002). MCMI-II profiles of women with eating disorders: a cluster analytic investigation. Journal of Personality Disorders, 16, 453-463. doi: 10.1521/pedi.16.5.453.22127

Flegal, K. M., Carroll, M. D., Ogden, C. L., \& Curtin, L. R. (2010). Prevalence and trends in obesity among US adults, 1999-2008. Journal of the American Medical Association, 303, 235-41. doi: 10.1001/jama.2009.2014

Friedman, M. A., \& Brownell, K. D. (1995). Psychological correlates of obesity: moving to the next research generation. Psychological Bulletin, 177, 3-20. doi: 10.1037/0033-2909.117.1.3

Gagnon-Girouard, M. P., Bégin, C., Provencher, V., Tremblay, A., Boivin, S. \& Lemieux, S. (2010). Subtyping weight-preoccupied overweight/obese women along restraint and negative affect. Appetite, 55, 742-745. doi: 10.1016/j.appet.2010.09.011

Garner, D. M. (1995). EDI-2 Eating Disorder Inventory-2, Manual. Florence: Organizzazioni Speciali.

Gormally, J. F., Black, S., Daston, S., \& Rardin, D. (1982). The assessment of binge eating severity among obese persons. Addictive Behaviors, 7, 47-55. doi: 10.1016/03064603(82)90024-7

Horowitz, L. M., Alden, L. E., Wiggins, J. S., \& Pincus, A. L. (2000). Inventory of Interpersonal Problems (IIP-32/IIP-64). London: Psychological Corporation.

Kalarchian, M. A., Marcus, M. D., Levine, M. D., Courcoulas, A. P., Pilkonis, P. A., Ringham, R. M., ... Rofey, D. L. (2007). Psychiatric disorders among bariatric surgery candidates: relationship to obesity and functional health status. American Journal of Psychiatry, 164, 328-334. doi: 10.1176/appi.ajp.164.2.328

Kasen, S., Cohen, P., Chen, H., Must, A. (2008). Obesity and psychopathology in women: a three decade prospective study. International Journal of Obesity, 32, 558-566. doi: 10.1038/sj.ijo.0803736

Kinzl, J. F., Schrattenecker, M., Traweger, C., Mattesich, M., Fiala, M., \& Biebl, W. (2006). Psychosocial predictors of weight loss after bariatric surgery. Obesity Surgery, 16, 16091614. doi: 10.1381/096089206779319301

Krueger, R. (1999). The structure of common mental disorders. Archives of General Psychiatry, 56, 921-926. doi: 10.1001/archpsyc.56.10.921

Lambert, M. J., Morton, J. J., Hatfield, D. R., Harmon, C., Hamilton, S., Shimokawa, K., ... Burlingame, G. B. (2004). Administration and scoring manual for the Outcome Questionnaire (OQ-45.2; 3rd ed.). Wilmington, DE: American Professional Credentialling Services, LLC.

Lo Coco, G., Gullo S., Salerno, L., \& Iacoponelli, R. (2011a). The association among interpersonal problems, binge behaviors, and self-esteem, in the assessment of obese individuals. Comprehensive Psychiatry, 52, 164-170. doi: 10.1016/j.comppsych.2010.06.002

Lo Coco, G., Gullo, S., Scrima, F., \& Bruno, V. (2011b). Obesity and interpersonal problems: an analysis with the interpersonal circumplex. Clinical Psychology \& Psychotherapy, 19,
390-398. doi: 10.1002/cpp.753.

Luppino, F. S., de Wit, L. M., Bouvy, P. F., Stijnen, T., Cuijpers, P., Penninx, B. W. J., \& Zitman, F. G. (2010). Overweight, obesity and depression: a systematic review and metaanalysis of longitudinal studies. Archive of General Psychiatry, 67, 220-229. doi: 10.1001/archgenpsychiatry.2010.2

Magee, C. A., \& Heaven, P. C. L. (2011). Big-five personality factors, obesity and 2-year weight gain in australian adults. Journal of Research in Personality, 45, 332-335. doi: 10.1016/j.jrp.2011.02.009

Mannucci, E., Ricca, V., Barciulli, E., Di Bernardo, M., Travaglini, R., Cabras, P. L., \& Rotella, C. M.. (1999). Quality of life and overweight: the obesity related well-being (ORWELL 97) questionnaire. Addictive Behaviors, 24, 345-357. doi: 10.1016/S0306-4603(98)00055-0

Marcus, M. D., \& Wildes, J. E. (2009). Obesity: Is it a mental disorder? International Journal of Eating Disorders, 42, 739753. doi: 10.1002/eat.20725

Mather, A. A., Cox, B. J., Enns, M. W., \& Sareen, J. (2008). Associations between body weight and personality disorders in a nationally representative sample. Psychosomatic Medicine, 70, 1012-1019. doi: 10.1097/PSY.0b013e318189a930

McNair, D. Lorr , M., \& Droppleman, L. (1971). Profile of Mood States. San Diego, CA: Educational and Industrial Testing Service.

Millon, T. (1997). MCMI-III, Millon Clinical Multiaxial Inventory-III Manual. Minneapolis: National Computer Systems.

OECD 2009. Health at a Glance 2009. Organisation for Economic Co-operation and Development.

Osman, A., Barrios, F. X., Kopper, B. A., Gutierrez, P. M., Williams, J. E., \& Bailey, J. (2006). The body assessment inventory (BIAI): development and initial validation. Journal of Clinical Psychology, 62, 923-942. doi: 10.1002/jclp.20273

Petry, N. M., Barry, D., Pietrzak, R. H., \& Wagner, J. A. (2008). Overweight and obesity are associated with psychiatric disorders: results from the national epidemiologic survey on alcohol and related conditions. Psychosomatic Medicine, 70, 288-297. doi: 10.1097/PSY.0b013e3181651651

Pickering, R., Grant, B. F., Chou, S. P., \& Compton, W. M. (2007). Are overweight, obesity, and extreme obesity associated with psychopathology? Results from the national epidemiologic survey on alcohol and related vonditions. Journal of Clinical Psychiatry, 68, 998-1009. doi: 10.4088/JCP.v68n0704

Prezza, M., Trombaccia, F. R., \& Armento, L. (1997). La scala dell'autostima di Rosenberg, traduzione e validazione italiana [Rosenberg self-esteem scale, the italian translation and validation]. Bollettino di Psicologia Applicata, 223, 35-44.

Provencher, V., Bégin, C., Gagnon-Girouard, M., Tremblay, A., Boivin, S., \& Lemieux, S., (2008). Personality traits in overweight and obese women: associations with BMI and eating behaviors. Eating Behaviors, 9, 294-302. doi: 10.1016/j.eatbeh.2007.10.004

Rosenberg, M. (1965). Society and the adolescent self-image. Princeton: Princeton University Press.

Rydén, A., Sullivan, M., Torgerson, J. S., Karlsson J., Lindroos, A. K., \& Taft, C. (2004). A comparative controlled study of personality in severe obesity: a 2 -years follow-up after intervention. International Journal of Obesity, 28, 1485-1493. doi: 10.1038/sj.ijo.0802768

Thompson-Brenner, H., Eddy, K. T., Franko, D. L., Dozer, D. J., Vashchenko, M., Kass, A. E., \& Herzog, D. B. (2008). A personality classification system for eating disorders: a longitudinal study. Comprehensive Psychiatry, 49, 551-560. doi: 10.1016/j.comppsych.2008.04.002

Thompson-Brenner, H., \& Westen, D. (2005). Personality subtypes in eating disorders: validation of a classification in a naturalistic sample. British Journal of Psychiatry, 186, 516524. doi: 10.1192/bjp.186.6.516

Sullivan, S., Cloninger, C. R., Przybeck, T. R., \& Klein, S. (2007). Personality characteristics in obesity and relationship 
with successful weight loss. International Journal of Obesity, 31, 669-674. doi: 10.1038/sj.ijo.0803464

Wilfley, D. E., Friedman, M. A., Dounchis, J. Z., Stein, R. I., Welch, R. R., \& Ball, S. A. (2000). Comorbid psychopathology in binge eating disorder: relation to eating disorder severity at baseline and following treatment. Journal of Consulting and Clinical Psychology, 68, 641-649. doi: 10.1037/0022006X.68.4.641

Wonderlich, S. A., Joiner, T. E., Keel, P. K., Williamson, D. A., $\&$ Crosby, R. D. (2007). Eating disorder diagnoses. empirical approaches to classification. American Psychologist, 62, 167180. doi: 10.1037/0003-066X.62.3.167
World Health Organization (2000). Obesity: preventing and managing the global epidemic. Technical report series no 894. Geneva: World Health Organization.

Zennaro, A., Ferracuti, S., Lang, M., \& Sanavio, E. (2008). L'adattamento italiano del MCMI-III. Studi di validazione [MCMI-III Italian adaptation]. Firenze: Organizzazioni Speciali.

Received November 23, 2012

Revision January 15, 2013

Accepted February 22, 2013 